\title{
Internal Propagation Behavior on the Turning Angles in Steel Pipes
}

\author{
Erkegali Amanbayev ${ }^{1}$, Bazartai Alimbayev², Bauyrzhan Manapbayev ${ }^{3}$, Raushan Djanuzakova ${ }^{4}$ \\ ${ }^{1}$ Department of Architecture and Construction Production M.KH. Dulati Taraz State University 080012, 7 Suleymenov \\ Str., Taraz, Republic of Kazakhstan. E-mail: amanbaev68@inbox.ru \\ ${ }^{2}$ Department of Construction and Production of Materials M.KH. Dulati Taraz State University \\ 080012, 7 Suleymenov Str., Taraz, Republic of Kazakhstan. E-mail: bazalim@mail.ru \\ ${ }^{3}$ Department of Construction and Production of Materials M.KH. Dulati Taraz State University 080012, 7 Suleymenov \\ Str., Taraz, Republic of Kazakhstan. E-mail: jiboj@mail.ru \\ ${ }^{4}$ Department of Automation and Telecommunication M.KH. Dulati Taraz State University 080012, 7 Suleymenov Str., \\ Taraz, Republic of Kazakhstan. E-mail: rdd-taraz@mail.ru
}

Corrosive damages can lead to accidents on pipelines in various industries. Therefore, the main objective of the work is to study the peculiarities of the development of internal corrosion at the corners of turns in steel pipes. The paper discusses the development of corrosion. It substantiates the primary importance of the development of corrosion on curved sections of steel pipes. It has been established that, in curvilinear areas, the rate of corrosion development depends on the rate of fluid flow, on the number of ions, and also on the effect of centrifugal force. The authors studied the average rate of corrosion development at the turns of hydraulic structures. Thus, the results obtained showed that the location of steel pipes of hydraulic structures affect the rate of corrosion development from inside the pipes.

Keywords: Corrosion, Steel pipes, Lorentz force, Wall thickness, Straight sections.

\section{Introduction}

In the history of construction and maintenance of steel pipes, there are accidents and failures due to corrosion damages $[29,17]$. The problem of corrosion is very urgent and is one of the main factors that cause major catastrophes and accidents on pipelines in various industries.

The main type of corrosion of pipes, which leads to damages, is internal corrosion. Corrosion prevention in steel pipes used in various industrial facilities is in application of insulating coatings both inside the pipes and outside. At that, attention is not paid to the corrosion propagation behavior in the curved sections of steel pipes.

The main internal corrosion studies were carried out in oil and gas and chemical industries, where the transportable medium rapidly leads to the internal corrosion $[12,31,16,37]$. Also, these studies are well developed in the studies of water and heat supply systems [10]. A lot of research has been carried out to this day and being carried out at the moment on the corrosion propagation in these industries, but these results cannot be generalized and used in hydraulic engineering structures due to the difference in the transportable media properties.

In [31] the author studies irrigation pressure pipe systems' life aging by means of forecasting the corrosion propagation danger of metal pipes transporting waste waters. In the work the emphasis is made on waste waters. It does not consider effect of corrosion propagation on the constructional metal pipe features.

The work [26] considers operation conditions of "Astrakhan-Mangyshlak" main internal surface conduit and properties of corrosion formation on it. The corrosion propagates due to water composition, temperature fluctuations and changes along the conduit length. The work does not consider effect of corrosion propagation on the constructional metal pipe features.
The work [24] notes that after long-term operation, localized corrosion damages occur on the oil and gas pipe pitches due to the transportable medium composition and movement influence, which can lead to the pipe rupture.

The works $[15,23,15]$ present results of experiments on the study of corrosion in the internal cavity of pipes, where the transportable medium flow regime and composition affect the pipe corrosion.

As the review of sources in this direction has shown, investigations of internal corrosion in hydraulic engineering structure pipes have not been adequately conducted, and there are practically no works on the study of the corrosion propagation on the curved sections of steel pipes.

\section{Methodology}

Our investigations $[1,30,6,7]$ showed that corrosion propagation occurs more intensively on the curved sections of steel pipes for various purposes than on the straight sections.

We have proposed corrosion propagation mechanism in steel structure elements in aqueous medium taking into account their ferromagnetic properties $[2,18,20]$. These studies showed that on the straight sections, ions of the transportable medium attracting by the Lorentz force to the walls of cracks start chemical process of steel elements' corrosion. Existing cracks on the outside are covered with oxide film forming iron hydroxides. Cracks filled with corrosion products on the straight sections are less susceptible to mechanical influences on the transportable medium. Therefore, here the corrosion propagation velocity is less than in the curved sections of steel pipes.

In the curved sections of steel pipes, a centrifugal force acts on moving particles (gases, mechanical impurities, water or other liquids) having a certain mass [28]. In the curved sections the corrosion propagation velocity 
depends on the liquid motion velocity, on the number of ions, and also on the centrifugal force effect equal to:

$$
F=\frac{m \cdot v^{2}}{R},
$$

where: $m$ - particle mass;

$v$ - particle motion velocity;

$R$ - radius of deformation.

These particles, acting mechanically, open cracks of steel pipes closed by the primary corrosion products and contribute to the further intensive corrosion propagation in them.

In the straight sections the corrosion propagation velocity depends only on the liquid flow velocity and on the number of ions, as $\frac{m \cdot v^{2}}{R} \rightarrow 0$, at $R=\infty$.

In the curved sections, where the turning angle equal to $90^{\circ}$, the corrosion propagation velocity depends on the liquid flow velocity, on the number of ions, as well as on the kinematic energy action, as $\frac{m \cdot v^{2}}{R} \rightarrow \max$, at
$R \rightarrow 0$ [28]. In this situation, the corrosion propagates several times more than in other curved sections, as the liquid motion before the angle changes and the number of ions increases. If previously on the straight sections, ions on the wetted perimeter of the pipe could act on the corrosion propagation velocity, then at turns to $90^{\circ}$, ions on the cross sectional area of the liquid can affect the corrosion propagation velocity.

To test the proposed mechanism for the corrosion propagation, we have conducted experiments to measure thickness of the steel pipes walls on the curved sections. The purpose of the experiment is to determine the turning angles, which have the greatest influence on the corrosion propagation velocity.

To this end, we have developed an apparatus for determining metal corrosion on the curved sections in steel pipes (Fig. 1). The apparatus consists of a pump welded at various angles of pipes $Ø 32 \times 3.0$ in diameter, a filter, an air valve and supports. The apparatus developed by us, where the liquid is circulated by the pump, has sections of steel pipes: straight, curved and with turn by $90^{\circ}$.

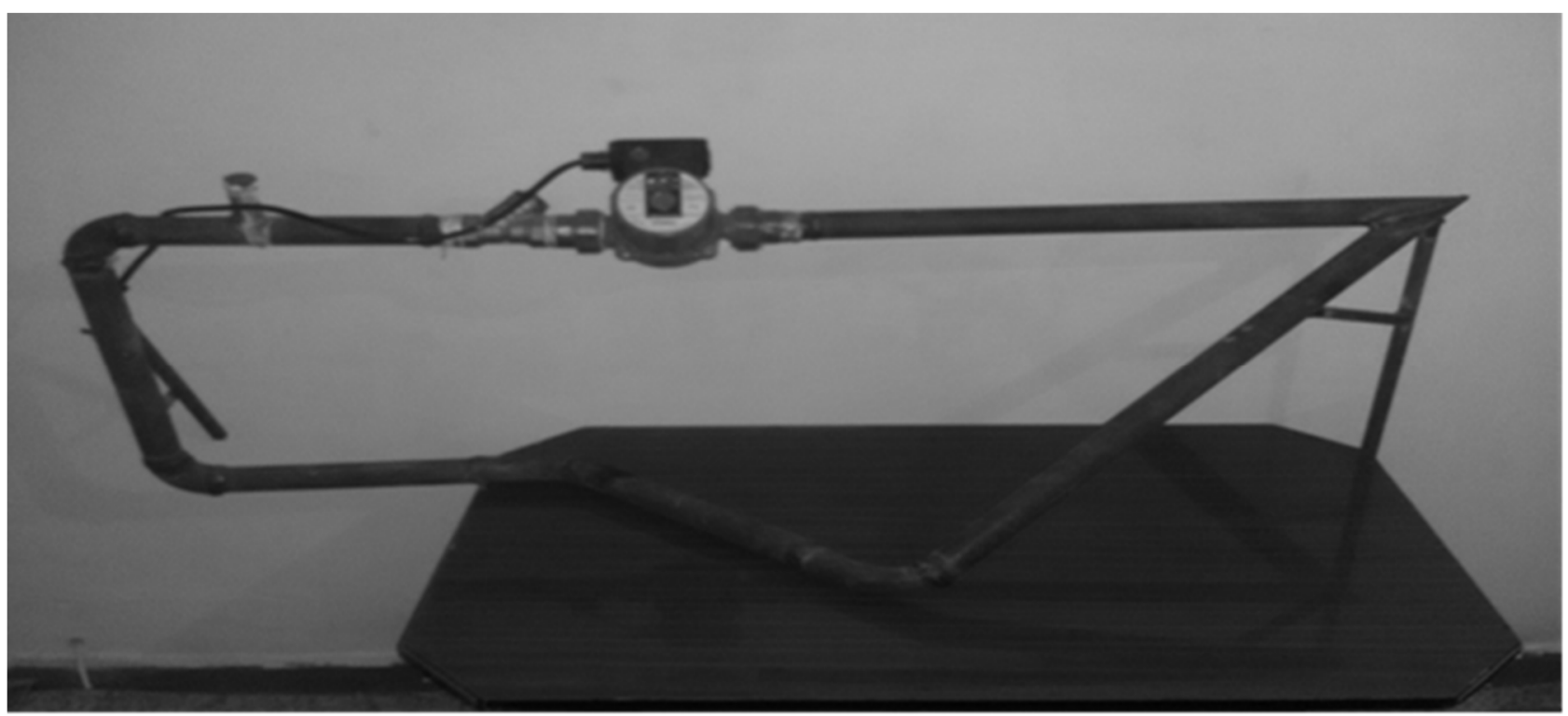

Fig. 1 The apparatus for determining metal corrosion on the curved sections in steel pipes

The experiment was conducted for one year. As is known, river water, fresh water have very weak ions, therefore, in order to obtain comparatively fast results in the role of a corrosive fluid, we took the salt solution, generally accepted in such experiments $(\mathrm{NaCl} 3.5 \%)$ [9,36].

It should be noted that in similar works [37,9], the salt solution $(\mathrm{NaCl} 3.5 \%)$ is used to study the corrosion propagation.

In the work [27], the salt solution $(\mathrm{NaCl} 3.5 \%)$ is also used for the experiment, but the work deals with the corrosion propagation in welded joints of pipes.

The thickness of the steel pipes walls was measured by ultrasonic thickness gage UT-301 according to GOST 28702-90. The converter is of $5 \mathrm{~B} 12 / 2-5.0 \mathrm{MHz}$ type. The main material of the pipe with $\varnothing 32 \times 3.0$ diameter is (Steel
10, GOST 1050-88). When measuring, the "echo" principle is used, i.e. the searcher and receiver are combined in one tester. The activated ultrasonic signals reach the internal pipe surface and are reflected by the receiver, knowing the propagation velocity and the time of passage of ultrasound on the metal, we have determined the wall thickness [37].

The layout of the measurement points in the apparatus is shown in Fig. 2. The apparatus is made of a $32 \mathrm{~mm}$ pipe, its wall thickness is $3 \mathrm{~mm}$, two angles of $90^{\circ}$, one angle is $135^{\circ}$, one angle is $120^{\circ}$, the sharp angle is $35^{\circ}$. The length of the upper pipe is $120 \mathrm{~cm}$, the height is 35 $\mathrm{cm}$, the lower length of the pipe is $36 \mathrm{~cm}$, the angle from this segment is $135^{\circ}$. The apparatus consists of five pipe sections. Its perimeter is $296 \mathrm{~cm}$.[26] 


\section{Results and discussion}

The apparatus was switched on in May 2016. There is a pump in the middle of the upper part that distills the salt solution. The pump is switched on via the time relay, it works continuously for 1 hour, stops for 20 minutes. The thickness of the pipe wall at 17 points was measured after 3 months (Table 1), 8 months (Table 2) and 1 year (Table 3 ). The thickness of the pipe wall was measured in the laboratory of ultrasonic testing (Testing laboratory of PKF FAN LLP, Taraz, Accreditation certificate No. KZ.I.08.1791).

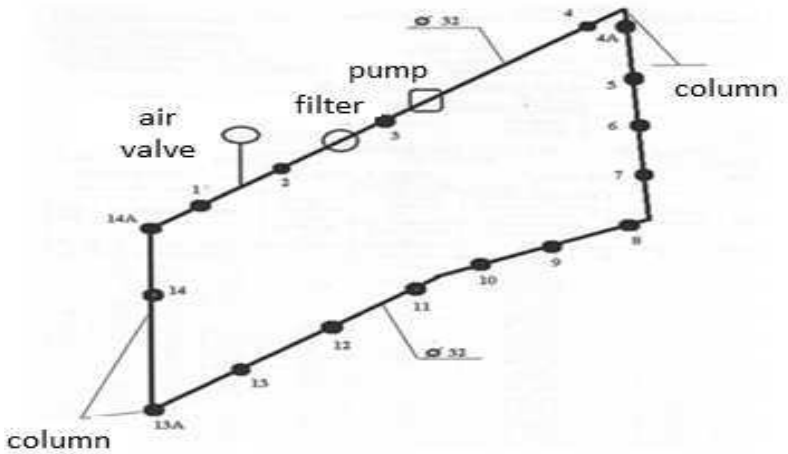

Fig. 2 The layout of the measurement points in the apparatus

Tab 1 The results of measuring the thickness of the steel pipes walls subjected to internal corrosion (August, 2016)

\begin{tabular}{|c|c|c|c|c|c|c|c|c|}
\hline \multirow{2}{*}{$\begin{array}{c}\text { No. } \\
1\end{array}$} & \multicolumn{3}{|c|}{$\begin{array}{l}\text { Measurement } \\
\text { value }(\mathrm{mm})\end{array}$} & \multirow{2}{*}{$\begin{array}{l}\text { Mean value } \\
\text { of three me- } \\
\text { asurements } \\
(\mathrm{mm})\end{array}$} & \multirow{2}{*}{$\begin{array}{l}\text { Thickness of the wall } \\
\text { taking into account } \\
\text { measurement errors } \\
(\mathrm{mm})\end{array}$} & \multirow{2}{*}{$\begin{array}{l}\text { Initial thickness of the } \\
\text { wall and diameter of } \\
\text { measured elements } \\
(\mathrm{mm})\end{array}$} & \multirow{2}{*}{$\begin{array}{c}\text { Retirement } \\
\text { size }(\mathrm{mm})\end{array}$} & \multirow{2}{*}{$\begin{array}{c}\text { Notice } \\
9\end{array}$} \\
\hline & 2 & 3 & 4 & & & & & \\
\hline 1 & 3.0 & 2.9 & 3.0 & 3.0 & 2.9 & $\varnothing 32 \times 3.0$ & $\delta=1.53$ & pipe \\
\hline 2 & 3.1 & 3.0 & 3.1 & 3.1 & 3.0 & $\varnothing 32 \times 3.0$ & $\delta=1.53$ & $-/ /-$ \\
\hline 3 & 3.0 & 2.9 & 3.0 & 3.0 & 2.9 & $\varnothing 32 \times 3.0$ & $\delta=1.53$ & $-/ /-$ \\
\hline 4 & 3.0 & 3.1 & 3.0 & 3.0 & 2.9 & $\varnothing 32 \times 3.0$ & $\delta=1.53$ & $-/ /-$ \\
\hline $4 \mathrm{~A}$ & 2.9 & 2.8 & 2.9 & 2.9 & 2.8 & $\varnothing 32 \times 3.0$ & $\delta=1.53$ & $-/ /-$ \\
\hline 5 & 2.9 & 2.8 & 2.9 & 2.9 & 2.8 & $\varnothing 32 \times 3.0$ & $\delta=1.53$ & $-/ /-$ \\
\hline 6 & 3.0 & 2.9 & 3.0 & 3.0 & 2.9 & $\varnothing 32 \times 3.0$ & $\delta=1.53$ & $-/ /-$ \\
\hline 7 & 3.1 & 3.0 & 3.1 & 3.1 & 3.0 & $\varnothing 32 \times 3.0$ & $\delta=1.53$ & $-/ /-$ \\
\hline 8 & 2.7 & 2.7 & 2.7 & 2.7 & 2.6 & $\varnothing 32 \times 3.0$ & $\delta=1.53$ & $-/ /-$ \\
\hline 9 & 2.7 & 2.8 & 2.7 & 2.7 & 2.6 & $\varnothing 32 \times 3.0$ & $\delta=1.53$ & $-/ /-$ \\
\hline 10 & 2.9 & 2.8 & 2.9 & 2.9 & 2.9 & $\varnothing 32 \times 3.0$ & $\delta=1.53$ & $-/ /-$ \\
\hline 11 & 3.0 & 2.9 & 3.0 & 3.0 & 2.9 & $\varnothing 32 \times 3.0$ & $\delta=1.53$ & $-/ /-$ \\
\hline 12 & 3.1 & 3.0 & 3.1 & 3.1 & 3.0 & $\varnothing 32 \times 3.0$ & $\delta=1.53$ & $-/ /-$ \\
\hline 13 & 2.7 & 2.7 & 2.7 & 2.7 & 2.6 & $\varnothing 32 \times 3.0$ & $\delta=1.53$ & $-/ /-$ \\
\hline $13 \mathrm{~A}$ & 2.7 & 2.7 & 2.7 & 2.7 & 2.6 & $\varnothing 32 \times 3.0$ & $\delta=1.53$ & $-/ /-$ \\
\hline 14 & 2.9 & 2.8 & 2.9 & 2.9 & 2.8 & $\varnothing 32 \times 3.0$ & $\delta=1.53$ & $-/ /-$ \\
\hline $14 \mathrm{~A}$ & 2.9 & 2.8 & 2.9 & 2.9 & 2.8 & $\varnothing 32 \times 3.0$ & $\delta=1.53$ & $-/ /-$ \\
\hline
\end{tabular}

Tab 2 The results of measuring the thickness of the steel pipes walls subjected to internal corrosion (February, 2017)

\begin{tabular}{|c|c|c|c|c|c|c|c|c|}
\hline \multirow{2}{*}{$\begin{array}{c}\text { No. } \\
1 \\
\end{array}$} & \multicolumn{3}{|c|}{$\begin{array}{l}\text { Measurement } \\
\text { value }(\mathrm{mm})\end{array}$} & \multirow{2}{*}{$\begin{array}{l}\text { Mean value of } \\
\text { three measure- } \\
\text { ments (mm) }\end{array}$} & \multirow{2}{*}{$\begin{array}{l}\text { Thickness of the } \\
\text { wall taking into ac- } \\
\text { count measurement } \\
\text { errors (mm) } \\
6\end{array}$} & \multirow{2}{*}{$\begin{array}{l}\text { Initial thickness of } \\
\text { the wall and diame- } \\
\text { ter of measured ele- } \\
\text { ments (mm) } \\
7\end{array}$} & \multirow{2}{*}{$\begin{array}{c}\text { Retirement } \\
\text { size }(\mathrm{mm}) \\
8\end{array}$} & \multirow{2}{*}{$\begin{array}{c}\text { Notice } \\
\\
9\end{array}$} \\
\hline & 2 & 3 & 4 & & & & & \\
\hline 1 & 3.0 & 2.9 & 3.0 & 3.0 & 2.9 & $\varnothing 32 \times 3.0$ & $\delta=1.53$ & pipe \\
\hline 2 & 3.0 & 2.9 & 3.0 & 3.0 & 2.9 & $\varnothing 32 \times 3.0$ & $\delta=1.53$ & $-/ /-$ \\
\hline 3 & 2.9 & 2.8 & 2.9 & 2.9 & 2.8 & $\varnothing 32 \times 3.0$ & $\delta=1.53$ & $-/ /-$ \\
\hline 4 & 2.9 & 2.9 & 2.9 & 2.9 & 2.8 & $\varnothing 32 \times 3.0$ & $\delta=1.53$ & $-/ /-$ \\
\hline $4 \mathrm{~A}$ & 2.2 & 2.3 & 2.2 & 2.2 & 2.1 & $\varnothing 32 \times 3.0$ & $\delta=1.53$ & $-/ /-$ \\
\hline 5 & 2.4 & 2.3 & 2.3 & 2.3 & 2.2 & $\varnothing 32 \times 3.0$ & $\delta=1.53$ & $-/ /-$ \\
\hline 6 & 2.9 & 3.0 & 2.9 & 2.9 & 2.8 & $\varnothing 32 \times 3.0$ & $\delta=1.53$ & $-/ /-$ \\
\hline 7 & 3.0 & 2.9 & 3.0 & 3.0 & 2.9 & $\varnothing 32 \times 3.0$ & $\delta=1.53$ & $-/ /-$ \\
\hline 8 & 2.4 & 2.3 & 2.4 & 2.4 & 2.3 & $\varnothing 32 \times 3.0$ & $\delta=1.91$ & $-/ /-$ \\
\hline 9 & 2.7 & 2.8 & 2.7 & 2.7 & 2.6 & $\varnothing 32 \times 3.0$ & $\delta=1.91$ & $-/ /-$ \\
\hline 10 & 2.8 & 2.9 & 2.8 & 2.8 & 2.7 & $\varnothing 32 \times 3.0$ & $\delta=1.91$ & $-/ /-$ \\
\hline 11 & 3.0 & 2.9 & 3.0 & 3.0 & 2.9 & $\varnothing 32 \times 3.0$ & $\delta=1.91$ & $-/ /-$ \\
\hline 12 & 3.0 & 2.9 & 3.0 & 3.0 & 2.9 & $\varnothing 32 \times 3.0$ & $\delta=1.53$ & $-/ /-$ \\
\hline 13 & 2.7 & 2.6 & 2.7 & 2.7 & 2.6 & $\varnothing 32 \times 3.0$ & $\delta=1.53$ & $-/ /-$ \\
\hline $13 \mathrm{~A}$ & 2.4 & 2.5 & 2.5 & 2.5 & 2.4 & $\varnothing 32 \times 3.0$ & $\delta=1.53$ & $-/ /-$ \\
\hline 14 & 2.4 & 2.5 & 2.4 & 2.4 & 2.3 & $\varnothing 32 \times 3.0$ & $\delta=1.53$ & $-/ /-$ \\
\hline $14 \mathrm{~A}$ & 2.3 & 2.3 & 2.4 & 2.3 & 2.2 & $\varnothing 32 \times 3.0$ & $\delta=1.53$ & $-/ /-$ \\
\hline
\end{tabular}


Tab 3 The results of measuring the thickness of the steel pipes walls subjected to internal corrosion (May, 2017)

\begin{tabular}{|c|c|c|c|c|c|c|c|c|}
\hline \multirow{2}{*}{$\begin{array}{c}\text { No. } \\
1\end{array}$} & \multicolumn{3}{|c|}{$\begin{array}{l}\text { Measurement } \\
\text { value }(\mathrm{mm})\end{array}$} & \multirow{2}{*}{$\begin{array}{l}\text { Mean value of } \\
\text { three measure- } \\
\text { ments }(\mathrm{mm}) \\
5\end{array}$} & \multirow{2}{*}{$\begin{array}{l}\text { Thickness of the } \\
\text { wall taking into } \\
\text { account measure- } \\
\text { ment errors } \\
(\mathrm{mm}) \\
6\end{array}$} & \multirow{2}{*}{$\begin{array}{l}\text { Initial thickness } \\
\text { of the wall and di- } \\
\text { ameter of mea- } \\
\text { sured elements } \\
(\mathrm{mm}) \\
7\end{array}$} & \multirow{2}{*}{$\begin{array}{l}\text { Retirement size } \\
(\mathrm{mm})\end{array}$} & \multirow{2}{*}{$\begin{array}{c}\text { Notice } \\
9\end{array}$} \\
\hline & 2 & 3 & 4 & & & & & \\
\hline 1 & 2.9 & 2.8 & 2.9 & 2.9 & 2.8 & $\varnothing 32 \times 3.0$ & $\delta=1.53$ & pipe \\
\hline 2 & 2.9 & 2.9 & 2.8 & 2.9 & 2.8 & $\varnothing 32 \times 3.0$ & $\delta=1.53$ & $-/ /-$ \\
\hline 3 & 2.9 & 2.8 & 2.9 & 2.9 & 2.8 & $\varnothing 32 \times 3.0$ & $\delta=1.53$ & $-/ /-$ \\
\hline 4 & 2.9 & 2.8 & 2.9 & 2.9 & 2.8 & $\varnothing 32 \times 3.0$ & $\delta=1.53$ & $-/ /-$ \\
\hline $4 \mathrm{~A}$ & 2.2 & 2.1 & 2.1 & 2.1 & 2.0 & $\varnothing 32 \times 3.0$ & $\delta=1.53$ & $-/ /-$ \\
\hline 5 & 2.1 & 2.2 & 2.2 & 2.2 & 2.1 & $\varnothing 32 \times 3.0$ & $\delta=1.53$ & $-/ /-$ \\
\hline 6 & 2.6 & 2.7 & 2.7 & 2.7 & 2.6 & $\varnothing 32 \times 3.0$ & $\delta=1.53$ & $-/ /-$ \\
\hline 7 & 2.9 & 2.8 & 2.9 & 2.9 & 2.8 & $\varnothing 32 \times 3.0$ & $\delta=1.53$ & $-/ /-$ \\
\hline 8 & 2.4 & 2.3 & 2.3 & 2.3 & 2.2 & $\varnothing 32 \times 3.0$ & $\delta=1.91$ & $-/ /-$ \\
\hline 9 & 2.7 & 2.8 & 2.7 & 2.7 & 2.6 & $\varnothing 32 \times 3.0$ & $\delta=1.91$ & $-/ /-$ \\
\hline 10 & 2.7 & 2.7 & 2.6 & 2.7 & 2.6 & $\varnothing 32 \times 3.0$ & $\delta=1.91$ & $-/ /-$ \\
\hline 11 & 2.8 & 2.7 & 2.7 & 2.7 & 2.6 & $\varnothing 32 \times 3.0$ & $\delta=1.91$ & $-/ /-$ \\
\hline 12 & 2.9 & 2.8 & 2.9 & 2.9 & 2.8 & $\varnothing 32 \times 3.0$ & $\delta=1.53$ & $-/ /-$ \\
\hline 13 & 2.8 & 2.7 & 2.7 & 2.7 & 2.6 & $\varnothing 32 \times 3.0$ & $\delta=1.53$ & $-/ /-$ \\
\hline $13 \mathrm{~A}$ & 2.4 & 2.5 & 2.4 & 2.4 & 2.3 & $\varnothing 32 \times 3.0$ & $\delta=1.53$ & $-/ /-$ \\
\hline 14 & 2.9 & 2.8 & 2.9 & 2.9 & 2.8 & $\varnothing 32 \times 3.0$ & $\delta=1.53$ & $-/ /-$ \\
\hline $14 \mathrm{~A}$ & 2.2 & 2.2 & 2.3 & 2.2 & 2.1 & $\varnothing 32 \times 3.0$ & $\delta=1.53$ & $-/ /-$ \\
\hline
\end{tabular}

Analysis of Tables 1, 2, 3 shows that at the points of measurement - No. 4A, 8, 13A, 14A, where the turning angles are sharp or equal to $90^{\circ}$, the wall thickness has significantly decreased. This shows that on the curved sections of steel pipes, corrosion propagates more strongly than on the straight sections, which in turn confirms the corrosion propagation mechanism proposed by us.

Corrosion inside steel pipes begins, as we established earlier [29, 2, 4], in the damaged areas. These areas with defects, non-uniformities, dislocations and cracks in steel structures, damage the ferromagnetic properties of steel. They, in turn, damage the domain structure of steel, and between the domains $\mathrm{Cl}^{-}$ions are attracted to the south poles, and $\mathrm{Na}^{+}$ions are attracted to the north poles, and thus corrosion begins, i.e. chemical process.

The pipe thickness in the first section decreased by 0,1 $\mathrm{mm}$ at the first measurement and the corrosion propagation velocity was equal to $\frac{0,1}{0,25}=0,4 \mathrm{~mm} /$ year . The corrosion propagation velocity in the second measurement was equal to zero. The corrosion propagation velocity in the third measurement was equal to $\frac{0,1}{0,353}=0,3 \mathrm{~mm} /$ year . The average corrosion propagation velocity in the steel pipes with the straight section was equal to $\frac{0,2}{1}=0,2 \mathrm{~mm} /$ year . After mathematical processing of thickness measurement results, we determined the corrosion propagation velocities in the steel pipes of the experimental apparatus on its straight sections, which are shown in Fig. 3.

At first straight sections of the steel pipes, the corrosion first developed actively, and then its propagation velocity slowed down. Then after a certain time, the corrosion propagation resumed. The resulting phenomenon is explained by the fact that when the ions passed through the cracks of domains after the first measurement, products of chemical reaction - micelles (chemical corrosion product) [4] formed and filled the cracks of domains, thereby reducing the corrosion propagation velocity.

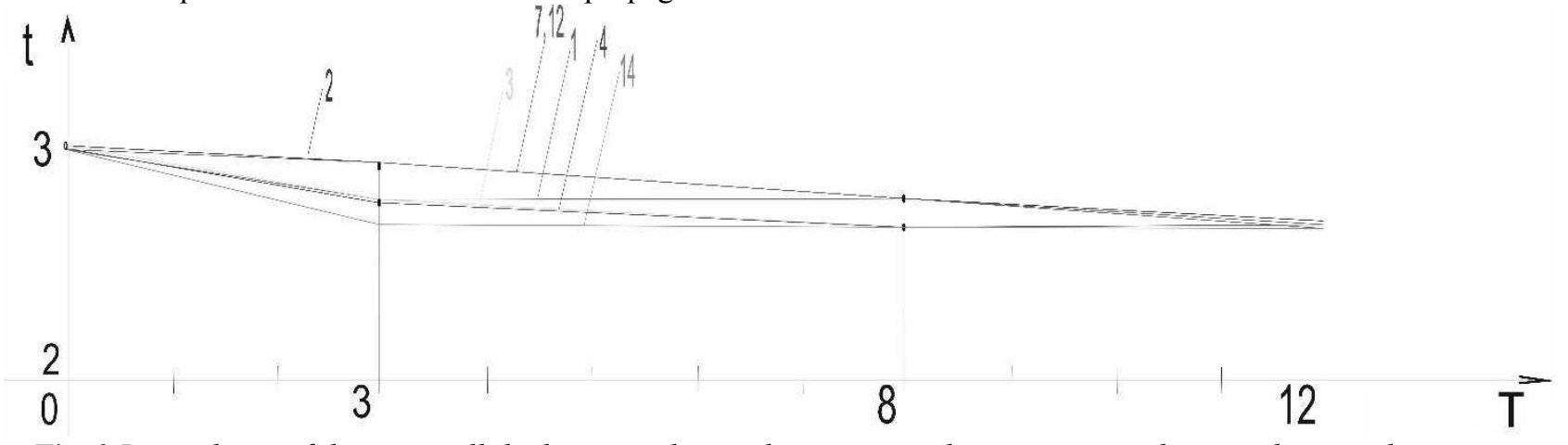

Fig. 3 Dependence of the pipe wall thickness on the residence time in the corrosive medium on the straight sections. The numbers correspond to the measurement points on the experimental apparatus. 
The average corrosion propagation velocity on the curved sections of the steel pipes of hydraulic engineering

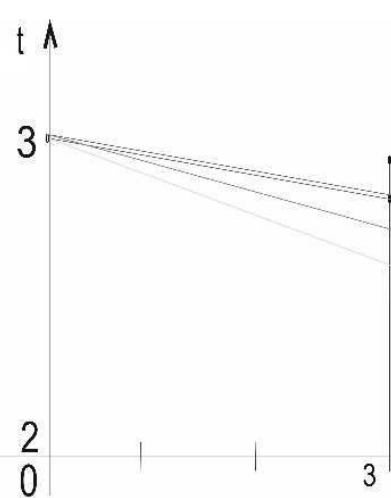

Fig. 4. Dependence of the pipe wall thickness on the residence time in the corrosive medium on the curved sections. The numbers correspond to the measurement points on the experimental apparatus.

The obtained value in comparison with the straight section of the steel pipes increased by $187.5 \%$. This phenomenon is explained by the fact that when turning the steel pipes, the liquid under the action of centrifugal forces hits the walls and wash out the micelles, and therefore the physical process does not stop, affecting the corrosion propagation velocity.

The average corrosion propagation velocity at the turns of the steel pipes of hydraulic engineering structures structures (Fig. 4) equal to $0.375 \mathrm{~mm} /$ year. equal to $90^{\circ}$ and is shown in Figure 5 and equal to 0.833 $\mathrm{mm} /$ year. [29]

The obtained value in comparison with the square section of the steel pipes increased by $416.5 \%$. This phenomenon is explained by the fact that when turning by $90^{\circ}$, the liquid completely breaks its structure, and the number of ions in the liquid increases in proportion to the ratio of the cylinder volume to its perimeter.[9]

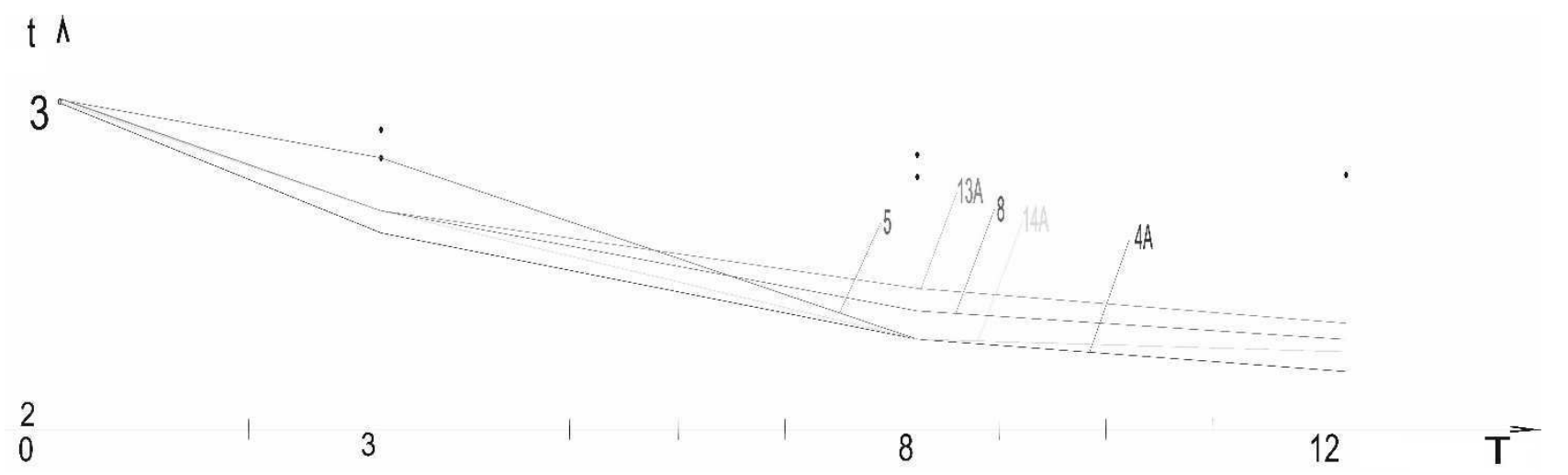

Fig. 5 Dependence of the pipe wall thickness on the residence time in the corrosive medium on the square sections. The numbers correspond to the measurement points on the experimental apparatus.

Thus, we obtained results showing that location of the steel pipes of hydraulic engineering structures affects the corrosion propagation velocity inside the pipes. This phenomenon was not taken into account when designing the steel pipes of hydraulic engineering structures, and reliability of the steel pipes depends on their location in space. In practice, elements of metal structures are designed to be equal in strength, while elements of metal structures of hydraulic engineering structures should be designed to have the same reliability and ensure trouble-free operation.

Calculation of tubular metal structures of hydraulic engineering structures is carried out according to the well-known formula of Laplace [13]:

$$
\frac{\sigma_{1}}{r_{1}}+\frac{\sigma_{2}}{r_{2}}=p t \text {, }
$$

where, $\sigma_{1}$ - meridian stress ;

$\sigma_{2}$ - circular stress;

$r_{1}$ - meridian radius;

$r_{2}$ - radius of curvature in the circular direction;

$p$ - pressure inside the pipe;

$t$ - thickness of the pipe walls.

The second component stress acting along the meridian direction is also determined for the pipes by the formula [13]:

$$
\sigma_{1}=\frac{p}{2 t}
$$

The pipes are in a plane stressed state, and the strength 
is tested by the following formula [13]:

$$
\sqrt{\sigma_{1}^{2}-\sigma_{1} \sigma_{2}+\sigma_{2}^{2}} \leq R_{y} \frac{\gamma_{c}}{\gamma_{n}}
$$

where, $R_{y}$-design strength of the steel, established by the yield point;

$\gamma_{c}$ - service factor;

$\gamma_{n}$ - reliability factor.

The calculation made by this formula does not ensure trouble-free operation of the pipes of hydraulic engineering structures, since it does not take into account the corrosion propagation inside the pipe.

\section{Conclusion}

The results of the above studies carried out by us in laboratories of M.Kh. Dulati Taraz State University showed that the pipes can lose their performance due to the corrosion. Pipes having turning angles, especially when they turn at the angle of $90^{\circ}$, may lose their troublefree operation earlier than the pipe sections having straight sections.

To eliminate this phenomenon, it is necessary to take measures ensuring equal reliability of all sections of tubular steel structures of hydraulic engineering structures, thus ensuring their trouble-free operation. ken:

In our opinion, the following measures should be ta-

- thicken pipes at the turning points;

- $\quad$ periodically paint pipes at the turning points;

- use in the turning points of pipes, steel of corrosion-resistant properties grades;

- continue to study the corrosion propagation on the curved sections of the steel pipes.

\section{References}

[1] ALIMBAYEV, B. A., MANABAYEV, B. J. (2012). The Development of corrosion in the elements of metal structures in the aquatic environment, p. 136, Taraz Universiteti, Taraz.

[2] ALIMBAYEV, B.A., MANAPBAEV, B.Z., ALIMBAYEVA, Z.B., DJANUZAKOVA, R.J. (2014). About one mechanism of development of corrosion in steel designs. In: Materials of the International Scientific Practical Conference, pp.111-118. Birmingham, United Kingdom.

[3] ALIMBAYEV, B.A., MANAPBAYEV, B.ZH., AMANBAYEV, E. (2016). The Mechanism of corrosion in steel structures in the aquatic environment. In: Materials of international scientificpractical conference "Reclamation and water management: problems and solutions" pp. 42-45.

[4] ALIMBAYEV, B.A., MANAPBAYEV, B.Zh., AMANBAYEV, E.N. (2017). Colloidal processes in the development of corrosion of steel in metal structures of hydraulic structure. In: Materials of the International Scientific Practical Conference, pp.173-176. Philadelphia, USA.

[5] ALIMBAYEV, B.A., MANAPBAYEV, B.ZH., DZHANUZAKOVA, R.ZH. (2013). Features corrosion in curved sections of steel pipes of hydraulic structures. In: University News, No. 2, pp. 1819.

[6] AMANBAYEV, E., ALIMBAYEV, B.A., MANAPBAYEV, B.ZH. (2016). Features of the development of corrosion on angles of bends in tubular steel structures. In: Bulletin of Architecture and Civil Engineering University, No 4, pp. 7175 .

[7] AMANBAYEV, E., ALIMBAYEV, B.A., MANAPBAYEV, B.ZH. (2018). The Influence of the location in the plane of the steel pipe of hydraulic engineering constructions on the speed of corrosion development. In: Bulletin of Architecture and Civil Engineering University, No 1, pp. 99-104.

[8] AUGUSTIN, Ya., SHLEDZEVSKY, E. (1978). Accidents Steel Structures, Stroyizdat, Moscow.

[9] AVAKYAN, L.G. (1955). From the experience of high-pressure pipelines operatio. In: Hydraulic Engineering, No 6, pp. 17-20.

[10] BALABAN-IRMENIN, YU.V., LIPOVSKIH, V.M., RUBASHOV, A.M. (1999). Protection against internal corrosion of pipelines of the water heating systems, Energoatomizdat, Moscow.

[11] BROŽE, M. (2018). Briquettes Properties after Four Years Storag. In: Journal Manufacturing Technology, Vol. 18, No. 1, pp. 11-15.

[12] ČARNOGURSKÁ, M., LÁZÁR, M., PŘÍHODA, M., SKOČILASOVÁ, B., KURILLA, P., MAREK, J. (2018) High-Temperature Processing and Recovery of $\mathrm{Cu}$ Catalyst Promoter. In: Manufacturing Technology, Vol. 18, No. 1, pp. 22-28.

[13] DONG, H.B., CHUL, H.K. (2004). Corrosion Fatigue Characteristics in the Weld of Multi-Pass Welded A106 Gr B Steel Pipe. In: KSME International Journal, Vol. 18, No. 1, pp. 114-121.

[14] EFIRD, K.D., WRIGHT, E.J., BOROS, J.A., HAILEY, T.G. (1993). Experimental correlation of steel corrosion in pipe flow with jet impingement and rotating cylinder laboratory tests. In: Corrosion 50, pp. 81/1-81/21.

[15] EVANS, U.R. (1972). An Introduction to Metallic Corrosion, Arnold, London.

[16] FAN, L., TANG, F., REIS, S.T., CHEN, G., KOENIGSTEIN, M.L. (2017). Corrosion Resistances of Steel Pipes Internally Coated with Enamel. In: Corrosion 73, pp. 1335-1345

[17] FONTANA, M.G. (1986). Corrosion Engineering, McGraw-Hill BookCompany, New York. 
[18] FRANKEL, G. Ya. (1970). Protection of the inner surface of pressure pipelines of hydroelectric power plants against corrosion and mineral deposits. In: Energy Construction, No 5, pp. 54-57.

[19] FREJSHIST, A.R. (1987). From the experience of the construction and operation steel pressure pipelines of hydraulic systems. In: Hydraulic Engineering, No 3, pp. 12-19.6

[20] FREJSHIST, A.R., MARTENSON, I.V., ROZINA, I.D. (1987). Increase of reliability of mechanical equipment and steelwork of hydraulic structures, p. 232, Energoatomizdat, Moscow

[21] HENTHORNE, M. (2016). The Slow Strain Rate Stress Corrosion Cracking Test-A 50 Year Retrospective. In: Corrosion 72, pp. 1488-1518.

[22] JEPSON, W.P. (1994). The effect of flow characteristics on sweet corrosion in high-pressure, three-phase, oil/water/gas horizontal pipelines. In: Prevention of Pipeline Corrosion Conference. Houston, Texas.

[23] JEPSON, W.P. (1997). Model for Sweet Corrosion in Horizontal Multiphase Slug Flow. In: Corrosion/97, No. 11, TX: NACE, Houston.

[24] KOSTYUCHENKO, A.A., BORDOVSKII, A.M., KOZIK, A.N., VOROB'EV, V.V., SOSNOVSKII, L.A. (2009). Experimental studies on the failure of oil pipes with inner surface corrosion defects. In: Strength of Materials, Vol. 41, No. 5, pp. 527-533.

[25] KOVÁČIKOVÁ, P., VAVRO, J., VAVRO, J.jr., DUBEC, A. (2018). Measuring of VibrationDamping Properties of Cast Iron. In: Manufacturing Technology, Vol. 18, No. 1, pp. 57-59.

[26] KUDISHIN, Y.I., BELINA, E.I. (2007). Metal construction, Academy, Moscow.37

[27] MANIVEL, P. (2017). The Influence of $\mathrm{H}+$ and $\mathrm{Cl}-$ Ions on the Corrosion Inhibitive Effect of Poly(para-aminophenol) for Iron in Hydrochloric acid. In: Corrosion Science and Technology, Vol. 16, No. 4, pp. 187-193.

[28] MARCUS, P. (2012). Corrosion mechanisms in theory and practice, CRC Press, U.S.
[29] MARTENSON, I.V. (1982). Questions of reliability of the mechanical equipment of hydraulic engineering constructions. In: Hydrotechnical Construction, No 2, pp. 10-11.

[30] MARTENSON, I.V. (1985). The results of the survey and experience in the operation of mechanical equipment of hydraulic structures. In: Hydraulic Engineering, No 10, pp. 34-37.

[31] ORLOVA, S.S., PANKOVA, T.A., KOCHETKOV, A.V. (2016). Differential study of the kinetics of corrosion processes in pipelines transporting wastewater. In: Hydraulic Engineering, No. 4, pp. $12-19$.

[32] PAKHOMOV, V.S., SHEVCHENKO, A.A. (2009). Chemical resistance of materials and corrosion protection, p. 448, Chemistry, Colossus, Moscow.

[33] PAPAVINASAM, S., DOIRON A., REVIE R.W. (2010). Model to Predict Internal Pitting Corrosion of Oil and Gas Pipelines. In: Corrosion 66, pp. 035006-035006-11.

[34] REFORMATSKAYA, I.I., ASHCHEULOVA, I.I., IVLEVA, G.A., TAUBALDIEV, T.S., MURINOV, S.K., TASTANOV, K.Kh., PRUTCHENKO, S.G., KOSTIN, D.V., ASTRAKHAN-MANGYSHLAK WATER CONDUIT. (2002). The Corrosion State on the Internal Surface and Methods for Its Corrosion Protection. Part I. Corrosion Deposits. In: Protection of Metals, Vol. 38, No. 6, pp. 590-594.

[35] REVIE, R.W. (E0d). (2011). Uhlig's corrosion handbook, Hoboken, New Jerse

[36] SAVELYEV, I.V. (2016). Course of physics. Mechanics. Molecular Physics, 352 p., LAN, Saint Petersburg.

[37] TAN, M.Yj, VARELA, F., HUO, Y., GUPTA, R., ABREU, D., MAHDAVI, F., HINTON, B., FORSYTH, M. (2016). An Overview of New Progresses in Understanding Pipeline Corrosion. In: Corrosion Science and Technology, Vol. 15, No. 6, pp. 271-280. 